\title{
Andiroba Oil (Carapa guianensis Aublet) Nanoemulsions: Development and Assessment of Cytotoxicity, Genotoxicity, and Hematotoxicity
}

\author{
Susana Suely Rodrigues Milhomem-Paixão, ${ }^{1,2}$ Maria Luiza Fascineli, ${ }^{3}$ \\ Luis Alexandre Muehlmann, ${ }^{3,4}$ Karina Motta Melo, ${ }^{5}$ Hugo Leonardo Crisóstomo Salgado, ${ }^{6}$ \\ Graziella Anselmo Joanitti, ${ }^{3,4}$ Julio Cesar Pieczarka, ${ }^{5}$ Ricardo Bentes Azevedo, ${ }^{3}$ \\ Alberdan Silva Santos, ${ }^{6}$ and Cesar Koppe Grisolia ${ }^{2}$ \\ ${ }^{1}$ Núcleo de Ensino e Pesquisa em Ciências Ambientais (NEPCA) do Instituto Federal de Educação, Ciência e Tecnologia de Goiás, \\ Campus Valparaiso de Goiás, Goiás, GO, Brazil \\ ${ }^{2}$ Laboratório de Genética Toxicológica, Departamento de Genética e Morfologia, Instituto de Ciências Biológicas, \\ Universidade de Brasília, Brasília, DF, Brazil \\ ${ }^{3}$ Laboratório de Nanobiotecnologia, Departamento de Genética e Morfologia, Instituto de Ciências Biológicas, \\ Universidade de Brasília, Brasília, DF, Brazil \\ ${ }^{4}$ Faculdade de Ceilândia, Universidade de Brasília, Brasília, DF, Brazil \\ ${ }^{5}$ Laboratório de Citogenética, Instituto de Ciências Biológicas, Universidade Federal do Pará, Belém, PA, Brazil \\ ${ }^{6}$ Laboratório de Investigação Sistemática em Biotecnologia e Biodiversidade Molecular (LabISisBio), \\ Instituto de Ciências Exatas e Naturais, Universidade Federal do Pará, Belém, PA, Brazil
}

Correspondence should be addressed to Susana Suely Rodrigues Milhomem-Paixão; susanamilhomem@yahoo.com.br Received 10 January 2017; Accepted 20 March 2017; Published 27 April 2017

Academic Editor: Sohel Rana

Copyright ( 2017 Susana Suely Rodrigues Milhomem-Paixão et al. This is an open access article distributed under the Creative Commons Attribution License, which permits unrestricted use, distribution, and reproduction in any medium, provided the original work is properly cited.

\begin{abstract}
Andiroba oil (AO) is obtained from an Amazonian plant and is used in traditional medicine. We carried out a comparative study to test the cytotoxicity, genotoxicity, and hematotoxicity of the oil and its nanoemulsion (AN) in vitro (fibroblasts, lineage $\mathrm{NIH} / 3 \mathrm{~T} 3$ ) and in vivo (Swiss mice). The AN was characterized by DLS/Zeta, and its stability was investigated for 120 days. The biological activity of AN was assessed in vitro by MTT test and cell morphology analyses and in vivo by micronucleus, comet, and hematotoxicity tests. The AN presented a hydrodynamic diameter (Hd) of $142.5 \pm 3.0$ and PDI of $0.272 \pm 0.007$ and good stability at room temperature. The MTT test evidenced the cytotoxicity of AO and of AN only at their highest concentrations, but AN showed lower cytotoxicity than AO. A lower cytotoxicity of $\mathrm{AN}$, when compared to $\mathrm{AO}$, is in fact an interesting data suggesting that during therapeutic application there will be a lower impact in the cell viability of healthy cells. Cytotoxicity, genotoxicity, and hematotoxicity were not observed in vivo. These tests on the biological and toxicological effects of andiroba oil and nanostructured oil are still initial ones but will give a direction to future application in cosmetics and/or the development of new phytotherapics.
\end{abstract}

\section{Introduction}

Carapa guianensis Aublet (Meliaceae), popularly known in Brazil as Andiroba, is a tree that has various traditional uses, such as an insect repellent and an anti-inflammatory and for healing wounds. The product of the andiroba tree that is most used for medicinal purposes is its oil, extracted from its seeds. It is rich in fatty acids, including oleic, palmitic, and linoleic acids [1]. The internal use was mainly recommended to combat flu, fever, asthma, and sore throat and even to lower the glucose level in the blood (diabetes) [2]. According to Ekor [3], it has increased the use of natural products 
in recent years; however, although the natural products are beneficial by their pharmacological activities, some products may produce the toxicity and adverse effect to the body and they need to be studied regarding these parameters.

There are few scientific data about the possible adverse effects or the safety of andiroba oil after experimental administration to animals. Among these studies, Costa-Silva et al. [4] carried out tests in Wistar rats for acute toxicity $(0.625-5.0 \mathrm{~g} / \mathrm{kg})$ and subacute toxicity $(0.375,0.75$, and $1.5 \mathrm{~g} / \mathrm{kg} /$ day, for 30 days), per os. Biochemical, hematological parameters and the weight of animals and organs were evaluated. In the acute test there was no type of symptom or death. In the subacute treatment there was an increase in the activity of plasma alanine amino transferase (ALT) and in the relative and absolute weight of the liver, results which indicate hepatotoxicity. Using Swiss mice, Milhomem-Paixão et al. [1] ran a subacute toxicity test $(0.5,1.0$, and $2.0 \mathrm{~g} / \mathrm{kg} /$ day for 14 days), also per os. Hematological, genotoxic, cytotoxic, and mutagenic parameters were evaluated, as well as the weight of the animals and their organs, and no toxicity was detected.

Worldwide, there is great interest from scientific communities and the pharmaceutical industry in developing drugs derived from plants. This interest has become even more evident with the development of new biotechnologies, such as nanobiotechnology [5]. Among the new tools provided by nanobiotechnology to natural product applications, nanoemulsions have been used to disperse oily extracts and compounds in aqueous media [6,7]. Nanoemulsions are isotropic nanometric formulations, based on oil, water, and surfactants, which have been used as carriers of bioactive compounds. Their long-term stability, ease of preparation, and high solubility of molecules have made them a promising tool in the development of pharmaceutical, cosmetic, and nutritional innovations [8-10]. Used in the production of cosmetics, they present advantages such as greater power to hydrate and to penetrate the skin with their active compounds [11]. In the food industry, products have been developed with ingredients that are difficult to absorb, due to their low solubility in water [10]. In the pharmaceutical industry, nanoemulsions can be used for controlled and directed release of drugs [12].

In the current scientific literature, to our knowledge, there are only three studies that refer to the development of nanoformulations with andiroba oil [13-15]. Other plant oils with therapeutic properties have been incorporated in nanomaterials, but few have been studied for their biocompatibility and toxicity $[9,14,16]$.

The aim of this work was to develop a nanoemulsion containing andiroba oil and to study its biocompatibility in vitro and in vivo. The data were compared with andiroba oil in natura. This report is the first in the literature to evaluate the effect of the nanoemulsification of andiroba oil on its toxicity profile.

\section{Material and Methods}

2.1. The Plant Material. The sample of andiroba oil (AO) was collected in the county of Uruará in Pará State (SUO3), with coordinates $\mathrm{S} 03^{\circ} 58^{\prime} 31.7^{\prime \prime} \mathrm{W} \quad 053^{\circ} 37^{\prime} 32.1^{\prime \prime}$ under license number MMA/ICMBIO/SISBIO-33336-1 issued by the Brazilian Environmental Agency. The seeds were collected in the months of March to July of 2012. The exsicates were deposited in the herbarium of the Brazilian Agricultural Research Company (Embrapa) under accession number 191736. The seeds were identified by Dr. Regina Celia Viana Martins da Silva, curator of the IAN Embrapa Amazônia Oriental herbarium. The andiroba oil was extracted for an artisanal extraction process [17]. More information about profile of fatty acids, steroids, triterpenes, and secondary metabolites like squalene, stigmasterol, cholesterol, epoxygedunin, 1,3dipalmitin, deoxylactone derivative, deacetylgedunin, and epoxydeacetylgedunin can be found in Milhomem-Paixão et al. [1].

2.2. Formulation of the Andiroba Nanoemulsion (AN). The nanoemulsion was prepared by a phase-inversion temperature (PIT) method [18, 19]. Briefly, 10 grams of $\mathrm{AO}$ and 20 grams of surfactant Kolliphor ${ }^{\circledR}$ ELP SIGMA were mixed under shaking. Next, 10 grams of Milli-Q water was added and the temperature was raised to $90^{\circ} \mathrm{C}$. It was confirmed that the solution had been clarified and another 10 grams of ice-cold Milli-Q water was added under shaking. As a control for the tests, a mineral oil nanoemulsion (liquid Nujol Petrolatum) was also developed, using the same methodology and the same quantity of oil, surfactant, and water.

2.3. Characterization of the Nanoemulsion (DLS/Zeta). The mean size of the particles was obtained using the Zetasizer Nano S, Malvern Instruments, based on the dynamic light scattering technique. The readings were carried out after $1: 100(\mathrm{~m}: \mathrm{v})$ dilution of the nanoemulsion in distilled water.

To analyze the stability of the nanoemulsion, three freshly prepared samples were separated and maintained at three different temperatures $\left(4^{\circ} \mathrm{C}, 37^{\circ} \mathrm{C}\right.$, and at room temperature $\mathrm{RT})$. For each sample, six readings with three replicates were done on the Zetasizer (7, 15, 30, 60, 90, and 120 days), and the parameters of the polydispersity index (PDI), zeta potential, and hydrodynamic diameter $(\mathrm{Hd})$ were obtained.

2.4. Cytotoxicity In Vitro Using the MTT Assay in Mouse Fibroblasts. The fibroblast cell lineage used was NIH/3T3 (ATCC). The cells were cultivated in Dulbecco's Minimum Essential Medium (DMEM) (Gibco) supplemented with 10\% of de Fetal Bovine Serum (FBS) and 1\% of antibiotic and then incubated with an atmosphere of $5 \%$ of $\mathrm{CO}_{2}$ at $37^{\circ} \mathrm{C}$, in plastic bottles of $25 \mathrm{~cm}^{3}$ volume.

To evaluate cytotoxicity, the MTT technique was used, a quantitative assay related to cell metabolic activity. Mitochondrial activity is quantified in a spectrophotometer, measuring the quantity of formazan crystals, which are formed by the reduction of MTT tetrazolium by live cells [20].

The fibroblasts of NIH/3T3 were obtained from cultures with $90-95 \%$ of confluence, and 3,000 cells/well were seeded in a 96-well plate. The whole experiment was carried out in triplicate. The cells were seeded with $100 \mu \mathrm{L}$ of DMEM supplemented with $10 \%$ of Fetal Bovine Serum (FBS) and 1\% 
of antibiotic for 24 hours, allowing it to adapt to the environment and the cells to adhere. After this period, the medium was removed from the plate, and $200 \mu \mathrm{L}$ of culture medium containing different concentrations ( 0.125 to $2.5 \mathrm{mg} / \mathrm{mL}$ ) of each treatment was added to each well: andiroba oil (AO) in natura; andiroba nanoemulsion (AN); mineral oil (MO); and mineral oil nanoemulsion (MON). The control group received only DMEM medium (10\% (FBS) and $1 \%$ of antibiotic). $\mathrm{AO}$ and $\mathrm{MO}$ were diluted in ethanol, and $\mathrm{AN}$ and MON were diluted in water, all in $1 \%$. According to Jo et al. [21] ethanol exposures at concentrations lower than $3 \%$ do not cause interference in the cell viability in primary glioblastoma cells. In our study ethanol and water were used at $1 \%$ as control, which really did not show any evidence of cytotoxicity to NIH/3T3, and showed also similar result with DMEM medium. Then, we used only one control.

The exposure was maintained for 24 and 48 hours. Cell viability was evaluated using a solution of yellow tetrazolium dye 3-(4,5-dimethylthiazolyl-2)-2,5-diphenyltetrazolium bromide (MTT) $(15 \mu \mathrm{L}$ of MTT for $135 \mu \mathrm{L}$ of DMEM per well for two hours). Next, the solution of DMEM plus MTT was removed and $100 \mu \mathrm{L}$ of DMSO was added. A Spectra Max Plate Reader was used to read the plates at $595 \mathrm{~nm}$. The percentage of cell viability was calculated by making a comparison in the number of viable cells between the controls and the treatments.

2.5. Test for Alteration of Cell Morphology. The morphological analysis of treated cells was carried out using an AxioVert.A1 inverted microscope from Zeiss; this was also used to photograph the cells with an AxioCam MRc camera, from Carl Zeiss Micro Imaging $\mathrm{GmbH}$. The exposures used for this test were $\mathrm{AO}, \mathrm{MO}, \mathrm{MON}, \mathrm{AN}$, and $\mathrm{ANC}$ (the latter being the andiroba nanoemulsion control which consisted of surfactant and water), all at concentrations of $1.25 \mathrm{mg} / \mathrm{mL}$ for $24 \mathrm{~h}$. This concentration was chosen because it was the one that demonstrated cell viability just below $50 \%$ in the MTT assay. Control group $\mathrm{C}$ did not receive a treatment.

2.6. In Vivo Tests. Nulliparous nonpregnant female Swiss mice (Mus musculus) were used, aged 12 weeks, bred at the bioterium at the State University of Campinas (UNICAMPSP-CEMIB). The project was approved by the Commission for Ethics in Animal Use (CEUA) of the Institute of Biological Sciences at the University of Brasília, UnBDoc, 127331/2013. The animals were kept in the conditions described in Milhomem-Paixão et al. [1].

2.7. Experimental Design. The animals were divided randomly into five experimental groups ( $n=6$ animals/group), consisting of the negative control, and groups receiving different doses of andiroba nanoemulsion (0.5, 1.0, and $2.0 \mathrm{~g} / \mathrm{kg} /$ day). The negative control group received only surfactant and water, and the treated animals received the andiroba nanoemulsion via a gastric tube (gavage). The administrations followed a period of 14 consecutive days, and the limit of concentration administered corresponds to what is recommended in guidelines 474 and 475 of the OECD
(Organization for Economic Cooperation and Development) for the evaluation of genotoxicity using micronucleus tests [22] and for chromosome aberrations of the bone marrow [23].

Throughout the whole experimental period, the animals were weighed and their consumption of foodstuffs was monitored every three days. Daily observations were made to check clinical symptoms arising from the treatment. After 14 days, the animals were sedated, and blood was taken for hematological evaluation and to make slides for the comet test. They were necropsied, and bone marrow from the femur was used for the micronucleus test, as described in MacGregor et al. [22, 23].

2.8. Genotoxicity and Mutagenicity Assays. The comet test followed the protocol established by Singh et al. [24] for alkaline comet $\mathrm{pH}>13$, with some modifications, as described in Milhomem-Paixão et al. [1]. The micronucleus test was carried out using bone marrow from the mice, following the protocols of Schmid [25], with modifications, as described in Milhomem-Paixão et al. [1].

2.9. Hematotoxicity. For the analysis of the hematological parameters, $370 \mu \mathrm{L}$ of the animals' blood with the anticoagulant EDTA (10\%) was submitted to an automatic veterinary hemocytometer (Sysmex pocH 100iV Diff ${ }^{\mathrm{fm}}$ ), calibrated for mice.

2.10. Statistical Analyses. The quantitative data were evaluated by parametric or nonparametric statistical tests, according to the distribution of normality. Parametric data were evaluated by Analysis of Variance (ANOVA) followed by Dunnett test. Nonparametric data were evaluated by Wilcoxon and then Kruskal-Wallis test. For this, the Graphpad Instat 3.02 program was used, considering significance to be of $p \leq 0.05$. The graphics and statistical analyses for MTT and for nanoemulsion characterizations were obtained on Graphpad Prism 5.

\section{Results}

3.1. Characterization of the Andiroba Nanoemulsion (AN): Mean Hydrodynamic Diameter, PDI, and Zeta Potential. The andiroba nanoemulsion obtained presented homogeneity and stability. The mean hydrodynamic diameter found was $142.5 \pm 3.0 \mathrm{~nm}$. The value of the PDI (polydispersity index) was $0.272 \pm 0.007$. The mineral oil nanoemulsion presented a hydrodynamic diameter of $610.9 \pm 3.0 \mathrm{~nm}$. The PDI was $0.169 \pm 0.04$.

Aiming to identify for how long and at what temperature this product remained stable, the characteristics of andiroba nanoemulsion were evaluated for 120 days. In relation to the PDI, there was greatest stability in the sample at room temperature and lowest stability at $4^{\circ} \mathrm{C}$. Regarding zeta potential, the sample at room temperature was the most stable and that at $37^{\circ} \mathrm{C}$ the least stable. For the diameter, the samples at room temperature and at $37^{\circ} \mathrm{C}$ were the most stable (Figure 1). 


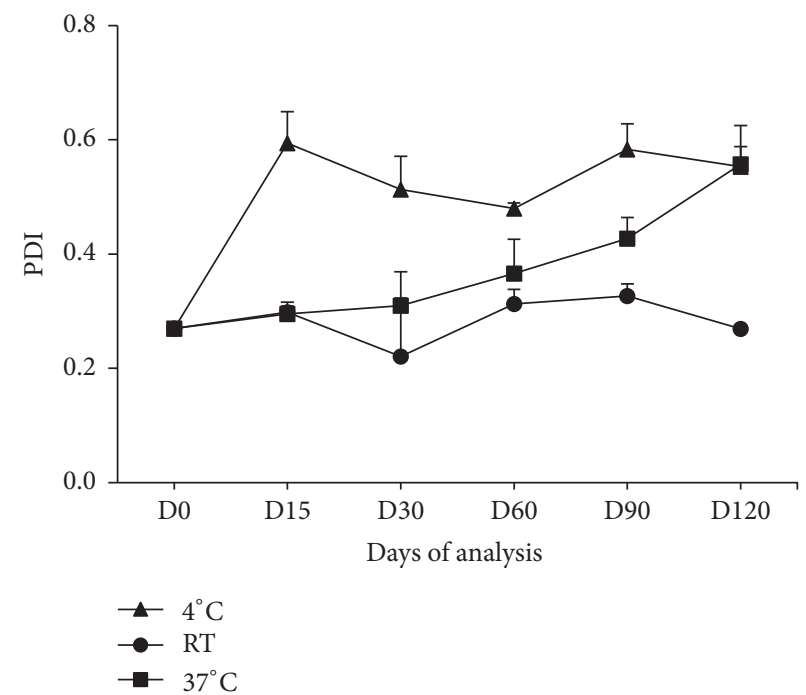

(a)
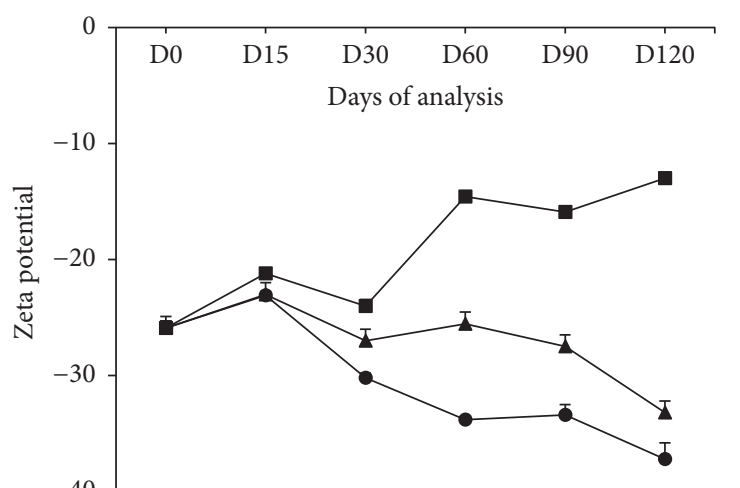

$\triangle 4^{\circ} \mathrm{C}$

$\rightarrow \mathrm{RT}$

$\rightarrow-37^{\circ} \mathrm{C}$

(b)

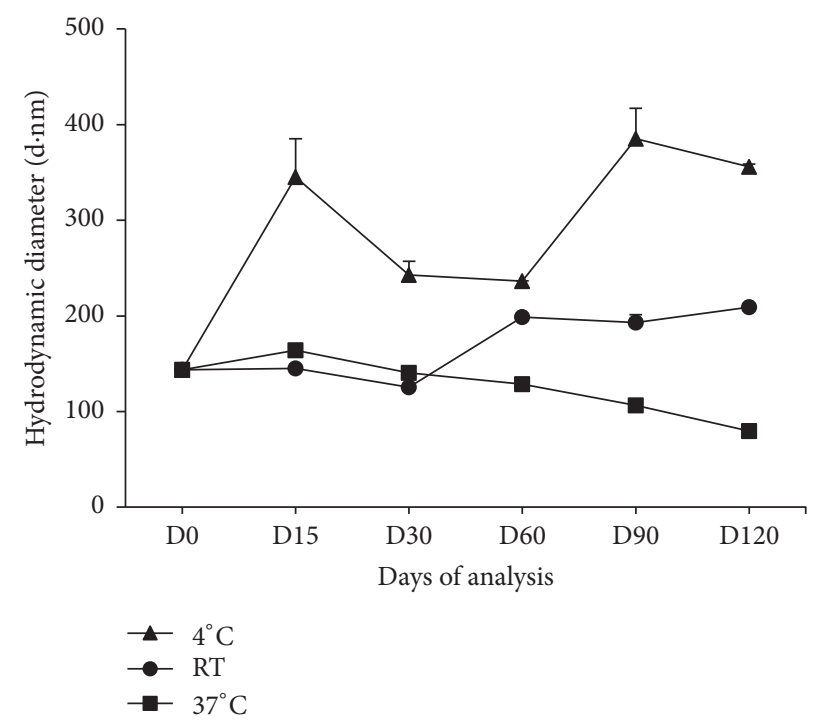

(c)

FIGURE 1: Distribution graphs for (a) PDI (polydispersity index), (b) zeta potential, and (c) hydrodynamic diameter of the nanoemulsion at three different temperatures obtained on the Zetasizer Nano S, Malvern Instruments, over a period of 120 days. d·nm: diameter in nanometer, AT: ambient temperature. The data represent the mean and standard deviation $(\bar{X} \pm S D)$.

\subsection{In Vitro Tests}

3.2.1. Cytotoxicity of the Oil In Natura and of the Andiroba Nanoemulsion. The AO and AN samples exhibited a concentration-dependent cytotoxicity profile, meaning that the greater the exposure concentration, the lower the cell viability. This effect was accentuated at 48 hours of exposure (Figure 2). However, the MO sample did not present a significant alteration at 24 and 48 hours of exposure in relation to the control and, in MON, the cell viability remained constant at all concentrations for 24 hours. After 48 hours of exposure, the MON presented small variation at the highest doses, but without a significant difference in relation to the control $(0 \mathrm{mg} / \mathrm{mL})$.
The IC50 values (50\% reduction in the cell viability) of the samples tested at 24 and 48 hours are also described in Figure 2 . The AO showed greater cytotoxicity than the AN. The entrapment of bioactive compounds in nanostructures can potentially alter their route of association or internalization to the targeted cell. Therefore, this is a possible explanation to the difference between the cytotoxicity of $\mathrm{AO}$ and $\mathrm{AN}$ in vitro. It was not possible to calculate the IC50 in the MO samples (24 and $48 \mathrm{~h}$ ) and MON (24h), because the concentrations used in the exposure were not great enough to reduce the cell viability by $50 \%$.

3.2.2. Cell Morphology after Exposure to the Treatments. Figure 3 represents the cell morphology of NIH/3T3 exposed 




(a)



(b)

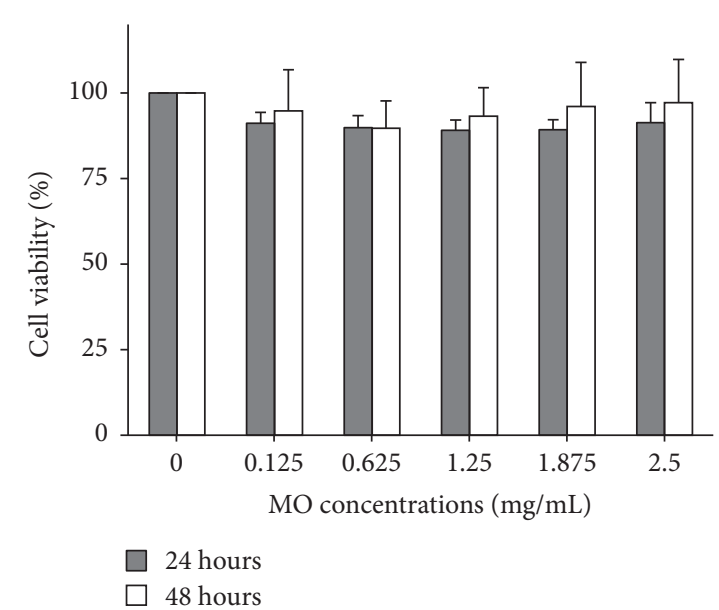

(c)

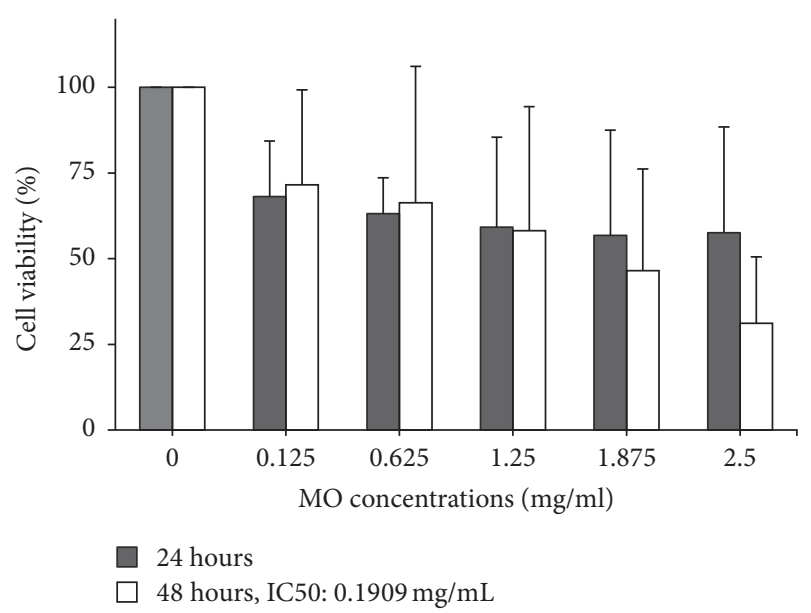

(d)

FIGURE 2: Evaluation of the cytotoxicity in NIH/3T3 fibroblasts of samples of (a) andiroba oil (AO) in natura; (b) andiroba nanoemulsion (AN); (c) mineral oil (MO); and (d) mineral oil nanoemulsion (MON), all at different concentrations, after 24 and 48 hours of exposure. The data are expressed by the mean and standard deviation. The statistical test used was ANOVA, in accordance with the distribution of normality. ${ }^{*} p<0.05$. The IC50 is described in the keys below the graph. The IC50 was obtained using a saturation curve.

at the concentration of $1.25 \mathrm{mg} / \mathrm{mL}$ for 24 hours and control group C. This concentration was chosen because it was the one that demonstrated cell viability slightly below $50 \%$ by MTT assay.

As can be observed, the morphology of the cells that were exposed to $\mathrm{AO}, \mathrm{ANC}$, and $\mathrm{AN}$ showed major alterations as those exposed to $\mathrm{MO}, \mathrm{MON}$, and the control. The cells that were exposed to $\mathrm{AO}, \mathrm{ANC}$, and $\mathrm{AN}$ can be seen in the smaller number of cells per field, showing that they were released during exposure. This demonstrates that there is an influence on cell morphology not only by the andiroba oil but also by the andiroba nanoemulsion and by the surfactant used in the production of the andiroba nanoemulsion. Probably AO, $\mathrm{ANC}$, and $\mathrm{AN}$ have a profound influence on cell membranes. However, the damaging action of surfactant on the MON is probably attenuated by the presence of the mineral oil and the larger size of oil droplets, because the MON cells are very similar to those of the control. It was also possible to see that in the AO and AN samples there is a large formation of lipid vacuoles in the cells. In AO there are more of these than in AN.

3.3. In Vivo Tests. To evaluate the possible toxicity arising from the administration of andiroba nanoemulsion, the mice were observed daily for possible alterations. However, no clinical or behavioral alteration was observed and nor were significant differences in body weight. No macroscopic alterations were observed during necropsy nor were alterations seen in the absolute or relative weight of the liver, spleen, or kidneys.

In this study, to characterize the genotoxicity/mutagenicity occasioned by exposure to the nanoemulsion, comet tests (Figure 4) and micronucleus tests (Table 1) were carried out. The results did not show significant alterations in the 

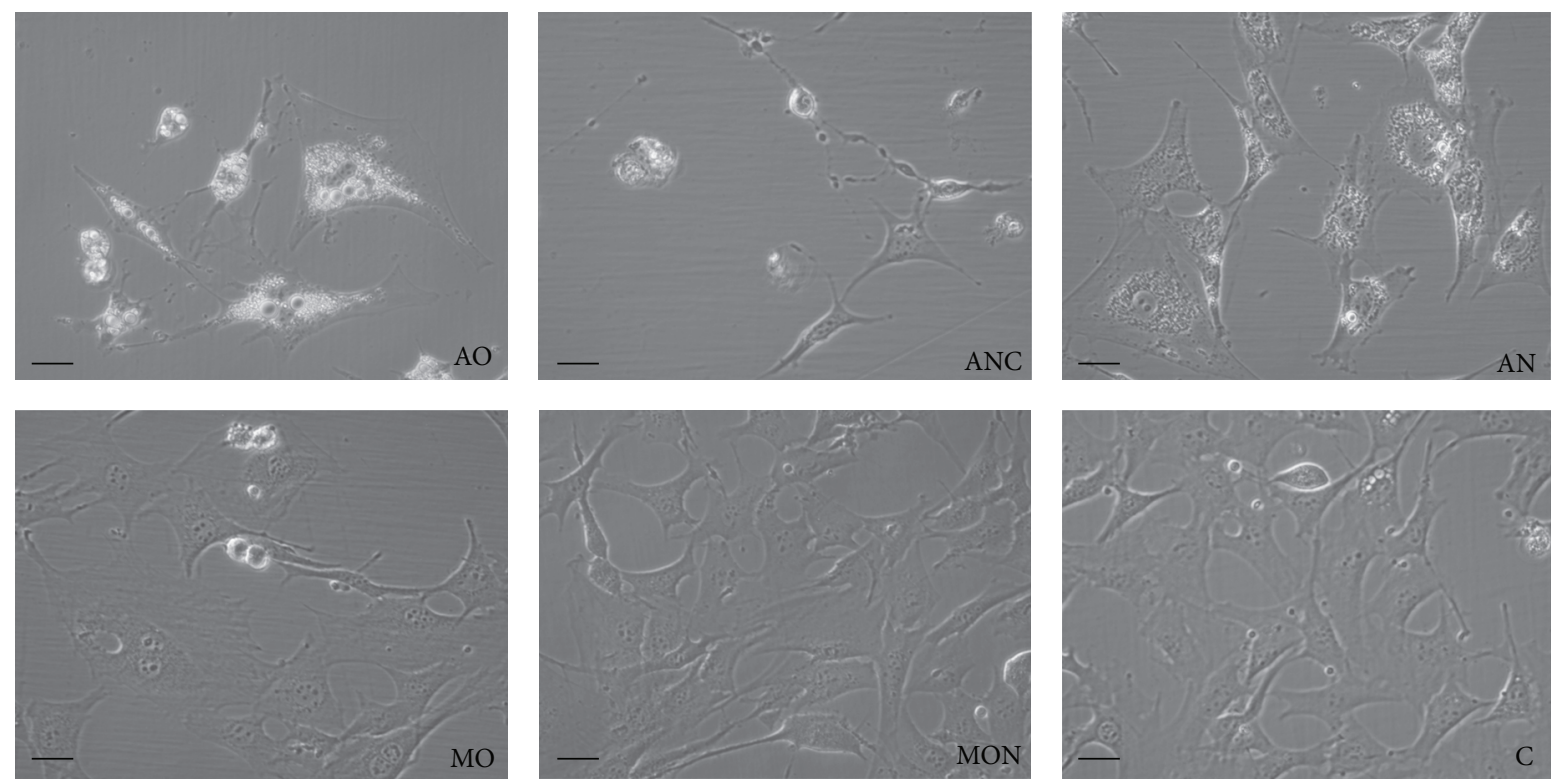

FIGURE 3: Morphology of NIH/3T3 cells after cultivation for 24 hours with the treatments at the third concentration $(1.25 \mathrm{mg} / \mathrm{mL}), \mathrm{AO}$ : andiroba oil, ANC: andiroba nanoemulsion control, AN: andiroba nanoemulsion, MO: mineral oil, MON: mineral oil nanoemulsion, and C: control. The scale bar corresponds to $10 \mu \mathrm{m}$.

TABLE 1: Frequency of micronuclei of Swiss mice after oral treatment for 14 days with andiroba oil nanoemulsion.

\begin{tabular}{lcccc}
\hline Treatments & Negative control & $0.5 \mathrm{~g} / \mathrm{kg}$ & $1 \mathrm{~g} / \mathrm{kg}$ & $2 \mathrm{~g} / \mathrm{kg}$ \\
\hline $\mathrm{N}^{\circ} \mathrm{MN}-\mathrm{PCE}$ & $1.33 \pm 1.51$ & $1.33 \pm 1.03$ & $2.00 \pm 1.55$ & $1.67 \pm 1.51$ \\
$\% \mathrm{MN}-\mathrm{PCE}$ & $6.64 \pm 7.49$ & $6.61 \pm 5.12$ & $10.40 \pm 8.70$ & $8.30 \pm 7.48$ \\
Relation PCE/NCE & $1.32 \pm 0.15$ & $1.37 \pm 0.21$ & $1.40 \pm 0.34$ & $1.49 \pm 0.23$ \\
\hline
\end{tabular}

The data are represented by the mean and standard deviation $(\bar{X} \pm$ SD). MN: micronucleus; PCE: polychromatic erythrocytes; NCE: normochromatic erythrocytes. Data were analyzed by ANOVA, in accordance with the distribution of normality, $p>0.05$.

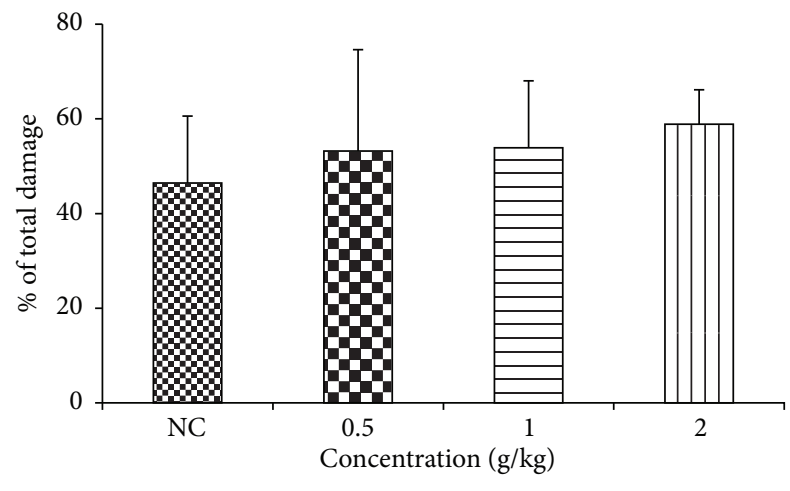

FIGURE 4: Comet test for mice treated orally with andiroba oil nanoemulsion for 14 days. The data represent the mean and standard deviation $(\bar{X} \pm S D)$. Data were analyzed by ANOVA, according to the distribution of normality, $p>0.05$. NC: negative control.

formation of micronuclei or fragmentation of the DNA molecule.

In the hematological evaluations no significant alteration was seen in the blood parameters (Table 2).

\section{Discussion}

In the current study, a nanoemulsion was formulated with oil of andiroba plant, which has an enormous cultural value and use in folk medicine in Amazonia. The nanoemulsion and the oil were tested for their biocompatibility, through the assessment of various parameters in vitro and in vivo.

Nanoemulsions are obtained by a number of preparation methods with different components. These methodologies can be divided into high and low-energy methods. Those that use high energy include microfluidization, high-pressure homogenization, and sonication. The low-energy methods involve spontaneous emulsification, solvent diffusion, and phase-inversion temperature. The ideal formulation should consider the safety of its components, as well as incorporating the dose required for the drug's best action and for it to remain stable over time [26].

Oliveira [13] produced a nanoemulsion based on andiroba oil, aiming to combat the mosquito Aedes aegypti, using a low-energy method, with Span and Tween as the surfactant. The Hd (hydrodynamic diameter) was less than $300 \mathrm{~nm}$, and the tests in humans showed positive results for insect repellent action. Lorca et al. [14] developed andiroba nanocapsules using the methodology of in situ 
TABLE 2: Erythrogram, leukogram, and plateletgram of Swiss mice treated orally with andiroba oil nanoemulsion.

\begin{tabular}{|c|c|c|c|c|}
\hline Parameters & Negative control & $0.5 \mathrm{~g} / \mathrm{kg}$ & $1 \mathrm{~g} / \mathrm{kg}$ & $2 \mathrm{~g} / \mathrm{kg}$ \\
\hline \multicolumn{5}{|l|}{ Erythrogram } \\
\hline $\mathrm{RBC} \times 10^{6} / \mu \mathrm{L}$ & $8.67 \pm 0.56$ & $9.17 \pm 0.27$ & $9.21 \pm 0.51$ & $9.16 \pm 0.36$ \\
\hline HGB g/dL & $12.27 \pm 0.81$ & $12.70 \pm 0.25$ & $12.97 \pm 0.82$ & $12.88 \pm 0.45$ \\
\hline НСТ\% & $31.58 \pm 2.18$ & $33.10 \pm 0.78$ & $33.58 \pm 2.30$ & $33.57 \pm 1.25$ \\
\hline MCV fL & $36.4 \pm 0.70$ & $36.1 \pm 0.76$ & $36.4 \pm 0.61$ & $36.7 \pm 0.34$ \\
\hline $\mathrm{MCH}$ pg & $14.2 \pm 0.3$ & $13.8 \pm 0.4$ & $14.1 \pm 0.3$ & $14.1 \pm 0.4$ \\
\hline $\mathrm{MCHC}$ g/dL & $38.8 \pm 0.58$ & $38.4 \pm 0.48$ & $38.6 \pm 0.72$ & $38.4 \pm 0.74$ \\
\hline RDW\% & $13.68 \pm 0.25$ & $13.73 \pm 0.85$ & $14.42 \pm 1.52$ & $13.20 \pm 0.48$ \\
\hline \multicolumn{5}{|l|}{ Leukogram } \\
\hline $\mathrm{WBC} \times 10^{3} / \mu \mathrm{L}$ & $1.83 \pm 0.63$ & $3.07 \pm 0.95$ & $3.10 \pm 0.89$ & $2.23 \pm 0.91$ \\
\hline W-SCR\% & $76.28 \pm 5.25$ & $73.43 \pm 9.40$ & $74.88 \pm 12.44$ & $74.23 \pm 6.55$ \\
\hline W-MCR\% & $19.23 \pm 3.42$ & $22.97 \pm 7.40$ & $23.00 \pm 11.67$ & $24.23 \pm 6.16$ \\
\hline W-LCR\% & $4.48 \pm 2.08$ & $3.60 \pm 3.11$ & $2.12 \pm 2.57$ & $1.53 \pm 1.55$ \\
\hline \multicolumn{5}{|l|}{ Plateletgram } \\
\hline $\mathrm{PLT} \times 10^{3} / \mathrm{mL}$ & $1132 \pm 270$ & $1326 \pm 287$ & $1414 \pm 190$ & $1251 \pm 129$ \\
\hline PDW fL & $6.88 \pm 0.32$ & $7.02 \pm 0.23$ & $6.80 \pm 0.16$ & $6.74 \pm 0.18$ \\
\hline MPV fL & $6.63 \pm 0.52$ & $6.48 \pm 0.19$ & $6.58 \pm 0.36$ & $6.26 \pm 0.24$ \\
\hline P-LCR\% & $9.25 \pm 3.72$ & $6.70 \pm 1.95$ & $9.02 \pm 3.02$ & $6.26 \pm 1.30$ \\
\hline
\end{tabular}

The data are represented by the mean and standard deviation $(\bar{X} \pm \mathrm{SD})$. The data were analyzed by ANOVA, in accordance with the distribution of normality, $p>0.05$. RBC: red blood cells; HGB: hemoglobin; HCT: hematocrit; MCV: mean corpuscular volume; MCH: mean corpuscular hemoglobin; MCHC: mean corpuscular hemoglobin concentration; RDW: red cell distribution width; g/dL: grams per deciliter; fL: femtoliters; pg: picogram; WBC: white blood cells; WSCR: lymphocytes; W-MCR: neutrophils + monocytes; W-LCR: eosinophils; PLT: platelets; PDW: platelet distribution width; MPV: mean platelet volume; PLCR: platelet large cell ratio.

polymerization of methyl methacrylate with different concentrations of the starter and different temperatures. The Hd varied from $192 \mathrm{~nm}$ to $321 \mathrm{~nm}$. The results demonstrated the viability of producing andiroba nanocapsules. Baldissera [15] developed a nanoemulsion based on andiroba oil, aiming to combat the Trypanosoma evansi, the etiological agent of the disease known as "Surra" or "Mal das cadeiras" in horses. The nanoemulsion of andiroba was prepared by the spontaneous emulsification method using Span and Tween as the surfactant and organic solvent (acetone). The hydrodynamic diameter (Hd) varied from $129.3 \mathrm{~nm}$ to $240.3 \mathrm{~nm}$, and the tests in Trypanosoma evansi showed positive results in two concentrations $(0.5 \%$ and $1.0 \%)$. In the present study, we obtained a nanoemulsion with a Hd lower than those described by Oliveira et al. $[13,14]$ and with Hd intermediate to that described by Baldissera et al. [15]. It is important to analyze the hydrodynamic diameter because it characterizes nanoformulations and allows assessing its stability over time and during dispersion necessary to toxicity experiments. This dispersion of nanoformulation can change Hd and "such changes may alter bioavailability or toxicity in ways that are not entirely understood" [27].

The method used in the present study was suitable for obtaining a nanoemulsion with good homogeneity and an excellent hydrodynamic diameter when compared to literature date [13-15], as well as maintaining its stability for more than four months, when stored at room temperature.

The stability of the material was accompanied by analysis of the PDI, hydrodynamic diameter, and zeta potential for four months. The value of the PDI indicates the distribution width of the sample size. The closer to zero it is, the lower the variation in the size of the nanoparticles [28]. From these data it was possible to conclude that the best storage temperature for the andiroba nanoemulsion is room temperature (RT). This temperature is also the same as that used by the Amazon population when conserving andiroba oil, as well as being the conservation temperature for other nanoemulsions described by Alam et al. [29-31]. On the other hand, the andiroba oil becomes solid at $4^{\circ} \mathrm{C}$, which could explain such variations, once our stock solution was stored at $4^{\circ} \mathrm{C}$, due to a possible precipitation in larger particulate compounds.

In the prediction of long-term stability of the nanoemulsion, it is necessary to understand the status of the nanoemulsion surface zeta potential. Nanoparticles with zeta potential values greater than $+25 \mathrm{mV}$ or lower than $-25 \mathrm{mV}$ typically have showed higher stability. On the other hand, dispersions with a low zeta potential value will eventually aggregate due to Van Der Waal interparticle attractions [28]. In this study, all samples showed stability until 30 days, regarding these parameters. Stability longer than 30 days was observed only in samples stored at $37^{\circ} \mathrm{C}$.

As for the analysis of cytotoxicity in vitro, it is very clearly established that lineage NIH/3T3 is a powerful tool for this type of study [32]. In the literature, different effects of the cytotoxic behavior have been described, depending on the type of chemical substance, concentration, system for delivering substances, and type of cell lineage, using the MTT assay, using NIH/3T3 and other kind of cells $[33,34]$. The AO and AN samples exhibited a higher concentration-dependent profile after 48 hours of exposure (Figure 2). However, the 
MO sample did not induce a significant alteration in cell viability at 24 and 48 hours in relation to the control. For the MON treatment, the cell viability remained constant at all the concentrations for 24 hours, and after 48 hours of exposure the MON presented a concentration-dependent variation in the highest concentrations. These results demonstrate a cytotoxic effect of the $\mathrm{AO}$, at the highest concentrations, and also of the surfactant used in producing the nanoemulsion. In relation to the MON, the toxic action of the surfactant is probably attenuated by the presence of the mineral oil, which was shown not to be cytotoxic. This result was also corroborated by the cell morphology after exposure (Figure 3) when we used the ANC (nanoemulsion control) made only with water and surfactant. The cytotoxicity of Cremophor EL has already been described for endothelial and epithelial cells, using the MTT test, with the endothelial cells being more sensitive than the epithelial cells [35]. Cremophor, similar to other surfactants, has a profound influence on cell membranes. They disturb plasma membranes or remove certain lipids from the membranes [35]. It is important to highlight in this study that the nanostructured oil (AN) showed less cytotoxicity than the andiroba oil (AO) at the $24 \mathrm{~h}$ and $48 \mathrm{~h}$ exposures. The entrapment of bioactive compounds in nanostructures can potentially alter their route of association or internalization to the targeted cell [36]. Therefore, this is a possible explanation to the difference between the cytotoxicity of $\mathrm{AO}$ and $\mathrm{AN}$ in vitro. According to Chime et al. [37], "an ideal drug delivery system fulfils the objective of maximizing therapeutic effect while minimizing toxicity." Our results demonstrated the efficacy of andiroba nanoemulsions as a delivery system, which can improve the efficiency of a drug, reducing their concentrations without losing effectiveness and minimizing side-effects [38].

It is important to emphasize that a low cytotoxicity of AN in normal cell does not necessarily implicate a reduced bioavailability of the bioactive compounds in in vivo systems. When used for a therapeutic application, nanostructures may accumulate in the desired target by taking advantage of intrinsic characteristics of the pathological process. For instance, it is known that nanoparticles can preferentially accumulate in inflammatory lesions, due the presence of abnormal blood vessels and reduced lymphatic drainage. This passive accumulation is known as EPR effect (enhanced permeation and retention) which contribute in increasing the amount of the bioactive compounds in the desired target [39].

After 24 hours of exposure, the inhibitory concentration $50 \%$ (IC50) for the AO was $0.5353 \mathrm{mg} / \mathrm{mL}$ and for the $\mathrm{AN}$ it was $1.191 \mathrm{mg} / \mathrm{mL}$. Comparing the value of the IC50 of the $\mathrm{AO}$ and $\mathrm{AN}$ at $24 \mathrm{~h}$ with data found in the literature, it can be noted that these values are higher than those described for other plant oils with high antiproliferative power. This is the case of guava (Psidium guajava) leaf oil in the KB lineage, of $0.0379 \mathrm{mg} / \mathrm{mL}$, and of basil (Ocimum basilicum) oil in the P388 lineage, of $0.0362 \mathrm{mg} / \mathrm{mL}$ [40]. AO and AN possess a lower antiproliferative power than guava leaf oil and basil oil. This result is of extreme importance in the development of a nanostructured cosmetic or pharmaceutical product with low cytotoxicity, and our results corroborate the studies that demonstrate that nanoemulsions present a reduction in toxicity. Moreno et al. [41] reported that lecithin-based microemulsions used for parenteral use showed reduced toxicity. Wang et al. [42] developed aclacinomycin A (EACM) emulsion and evaluated its toxicity in M5076 tumorbearing C57BL/6 mice. E-ACM had lower acute toxicity and greater potential antitumor effects than F-ACM (the free ACM). Bruxel et al. [26] also report that some studies with nanoemulsions describe possibilities in toxicity reduction, increased activity, therapeutic window, bioavailability, and controlled release of drugs.

The nanoemulsions used in the production of cosmetics present the following advantages: greater power to moisturize and for active ingredients to penetrate; uniform distribution of the product over the skin; capacity to penetrate wrinkles; sensorial aspect; transparency and fluidity; ability to carry a fragrance; and perfumes without alcohol, and follicular, and pilosebaceous penetration $[43,44]$. In the development of repellent nanoemulsions, they present greater efficacy in the action against insects [45]. In the case of $\mathrm{AN}$, these actions need to be proved with specific tests against insects.

Andiroba oil possesses various uses in traditional medicine, mainly as an anti-inflammatory and a wound healer. Even without scientific studies, the Amazonian population uses this oil indiscriminately in natura and even in capsules. Because of this, here in this study the route of administration chosen for andiroba nanoemulsion (AN) was oral. The oral administration of surfactants is relatively safe. Here, this route via a gastric tube (gavage) was tested in vivo (Swiss mice). As could be observed in the initial results for cytotoxicity by MTT and cell morphology, the oil presents a concentration-dependent cytotoxic effect. With the data obtained in vitro it is not possible to affirm whether the andiroba oil and its nanoemulsion are suitable for use in humans, due to the cell death observed. Additional in vivo toxicity tests are needed to establish the concentrations that will allow safe use. In the in vivo study model, there is a complex of processes that occur in the gastrointestinal tract, affecting the absorption of the analyte, which does not happen in vitro, where the dissolution and absorption of the drug can be immediate [46].

In our studies, administration in the mice was carried out for a period of 14 consecutive days. The analyzed concentration limit is in accordance with the recommendations indicated in guidelines 474 and 475 of the OECD (Organization for Economic Cooperation and Development) for the evaluation of genotoxicity from micronucleus test [22] and of chromosome aberrations in bone marrow [23], as also described in Milhomem-Paixão et al. [1].

Oxidative species, as well as various natural compounds or medicines, can interact with DNA, causing damage. The damage can be reverted by the DNA repair system or may persist, inducing genotoxicity and even mutagenesis. To evaluate the mutagenic and genotoxic effects of numerous compounds, comet and micronucleus tests are well established in the indication of the extent and severity of the interaction between the compounds studied and DNA [47, 48]. Furthermore, these tests are validated by international agencies that evaluate the safety of chemical agents. 
The PCE/NCE (polychromatic erythrocyte/normochromatic erythrocyte) relationship is another parameter that can be evaluated by the micronucleus test. The progression of erythroblasts from the PCE to the NCE stage is an indicator of the acceleration or inhibition of erythropoiesis, and thus a reduction in this relationship (PCE/NCE) indicates cytotoxicity [49]. The results of the experiment by MilhomemPaixão et al. [1] showed that andiroba oil did not induce a significant increase in the MN-PCE frequency and did not reduce the PCE/NCE relationship at any of the tested concentrations. All the tested samples of andiroba oil in natura and of the nanoemulsion indicate a negative result for the micronucleus test, which means that these samples did not induce structural or numerical chromosome damage in the erythroblasts of Swiss mice treated with andiroba and nor did they present cytotoxicity in the bone marrow. The comet assay for the experiments of Milhomem-Paixão et al. [1] and those described here in this study also demonstrated that the substances tested did not produce DNA breakages in blood cells of mice during administration at the maximum dose of $2 \mathrm{~g} / \mathrm{kg}$ for 14 days. The results show that andiroba oil and nanoemulsion are not genotoxic, cytotoxic, or mutagenic. These results are similar to those found for other plant oils such as Copaíba oil of the genus Copaifera [50] and the oil extracted from fruit of the species Litsea cubeba [51]. Similar results were observed in Swiss mice treated with a nanoemulsion made from the oil of the Sucupira tree Pterodon emarginatus Vogel [52].

In this study, as well as in our previous work, both andiroba nanoemulsion and andiroba oil in natura presented no hematotoxicity in mice [1].

Even with the detection of the high antioxidant potential of AO described by Milhomem-Paixão et al. [1] it could be noted that the cytotoxicity test in vitro showed that andiroba oil and nanoemulsion have a cytotoxic effect only at high concentrations, which was not seen in in vivo tests. This difference may have occurred because of the forms of absorption in the samples tested here. In vitro, there is no barrier to the absorption of the compounds by the cells, while in vivo the absorption is a complex process, involving the interaction of the compounds with the gastrointestinal tract, their transport to organs, hepatic first pass effect, and other events. This process may have prevented or obstructed the delivery of the andiroba compounds to the blood cells, in the case of comet and hematoxicity analysis, in the bone marrow cells, and in the case of the micronucleus test.

\section{Conclusion}

In conclusion, this work reports the development of a stable nanoemulsion produced with andiroba oil. In the experimental biological conditions used in vivo in this work, a nanoemulsion did not present genotoxic, cytotoxic, or mutagenic effects, whereas in the in vitro tests it presented cytotoxicity at the highest concentrations.

These tests on the biological and toxicological effects of andiroba oil and nanostructured oil will give a direction to future application in cosmetics and/or the development of new phytotherapics. The data presented here are still initial ones, but as studies advance, bringing greater knowledge about the properties and applications of this oil, more value may be given to the andiroba tree.

\section{Conflicts of Interest}

The authors declare that they have no conflicts of interest.

\section{Acknowledgments}

This research was supported by the National Council for the Improvement of Higher Education (CAPES) from the ProAmazonia Project no. 3284/2013 and by the National Council for Scientific and Technological Development (CNPq). Susana Suely Rodrigues Milhomem-Paixão received a Postdoctoral Fellowship from the National Council for Scientific and Technological Development (CNPq).

\section{References}

[1] S. S. R. Milhomem-Paixão, M. L. Fascineli, M. M. Roll et al., "The lipidome, genotoxicity, hematotoxicity and antioxidant properties of andiroba oil from the Brazilian Amazon," Genetics and Molecular Biology, vol. 39, no. 2, pp. 248-256, 2016.

[2] A. P. Mendonça and I. D. K. Ferraz, "Óleo de andiroba: processo tradicional da extração, uso e aspectos sociais no estado do Amazonas, Brasil," Acta Amazonica, vol. 37, no. 3, pp. 353-364, 2007.

[3] M. Ekor, "The growing use of herbal medicines: issues relating to adverse reactions and challenges in monitoring safety," Frontiers in Neurology, vol. 4, article 177, 2014.

[4] J. H. Costa-Silva, C. R. Lima, E. J. R. Silva et al., "Acute and subacute toxicity of the Carapa guianensis Aublet (Meliaceae) seed oil," Journal of Ethnopharmacology, vol. 116, no. 3, pp. 495500, 2008.

[5] P. D. Marcato, "Pharmacokinetics and Pharmacodynamics of Nanomaterials," in Nanotoxicology: Materials, Methodologies, and Assessments, pp. 97-110, Springer, New York, NY, USA, 2014.

[6] L. A. Muehlmann, M. C. Rodrigues, J. P. F. Longo et al., "Aluminium-phthalocyanine chloride nanoemulsions for anticancer photodynamic therapy: development and in vitro activity against monolayers and spheroids of human mammary adenocarcinoma MCF-7 cells," Journal of Nanobiotechnology, vol. 13, article 36, 2015.

[7] M. C. Rodrigues, "Photodynamic therapy based on Arrabidaea chica (Crajiru) extract nanoemulsion: in vitro activity against monolayers and spheroids of human mammary adenocarcinoma MCF-7 cells," Journal of Nanomedicine \& Nanotechnology, vol. 6, no. 3, article 286, 2015.

[8] A. Azeem, M. Rizwan, F. J. Ahmad et al., "Nanoemulsion components screening and selection: a technical note," AAPS PharmSciTech, vol. 10, no. 1, pp. 69-76, 2009.

[9] C. E. S. Silva, O. J. Dos Santos, J. M. Ribas-Filho et al., "Effect of Carapa guianensis aublet (Andiroba) and orbignya phalerata (babassu) in colonic healing in rats," Revista do Colégio Brasileiro de Cirurgiões, vol. 42, no. 6, pp. 399-406, 2015.

[10] A. Gupta, H. B. Eral, T. A. Hatton, and P. S. Doyle, "Nanoemulsions: formation, properties and applications," Soft Matter, vol. 12, no. 11, pp. 2826-2841, 2016. 
[11] O. Sonneville-Aubrun, J.-T. Simonnet, and F. L'Alloret, "Nanoemulsions: a new vehicle for skincare products," Advances in Colloid and Interface Science, vol. 108-109, pp. 145-149, 2004.

[12] S. Tamilvanan, "Formulation of multifunctional oil-in-water nanosized emulsions for active and passive targeting of drugs to otherwise inaccessible internal organs of the human body," International Journal of Pharmaceutics, vol. 381, no. 1, pp. 6276, 2009.

[13] B. R. Oliveira, Desenvolvimento e avaliação de nanoemulsões com óleos de Carapa guianensis e Copaifera sp. e estudo de ação repelente frente a Aedes aegypti [M.S. thesis], Faculdade de Ciências Farmacêuticas de Ribeirão Preto, 2008.

[14] B. S. S. Lorca, C. Sayer, P. H. H. Araújo, M. Nele, and J. C. Pinto, "Nanoencapsulação de óleo de andiroba viapolimerização em miniemulsão," in Anais do 10 Congresso Brasileiro de Polímeros, Foz do Iguaçu, Brazil, 2009, https://www.ipen.br/ biblioteca/cd/cbpol/2009/PDF/761.pdf.

[15] M. D. Baldissera, A. S. Da Silva, C. B. Oliveira et al., "Trypanocidal activity of the essential oils in their conventional and nanoemulsion forms: in vitro tests," Experimental Parasitology, vol. 134, no. 3, pp. 356-361, 2013.

[16] I. C. Costa, R. F. Rodrigues, F. B. Almeida et al., "Development of jojoba oil (Simmondsia chinensis (link) C.K. schneid.) based nanoemulsions," Latin American Journal of Pharmacy, vol. 33, no. 3, pp. 459-463, 2014.

[17] P. Shanley, M. Serra, and G. Medina, Frutíferas e Plantas Úteis na Vida Amazônica, Editora Supercores, Belém, Brazil, 2005, http://www.fca.unesp.br/Home/Extensao/GrupoTimbo/ frutiferas.pdf.

[18] T. Tadros, P. Izquierdo, J. Esquena, and C. Solans, "Formation and stability of nano-emulsions," Advances in Colloid and Interface Science, vol. 108-109, pp. 303-318, 2004.

[19] P. P. Constantinides, M. V. Chaubal, and R. Shorr, "Advances in lipid nanodispersions for parenteral drug delivery and targeting," Advanced Drug Delivery Reviews, vol. 60, no. 6, pp. 757$767,2008$.

[20] T. Mosmann, "Rapid colorimetric assay for cellular growth and survival: application to proliferation and cytotoxicity assays," Journal of Immunological Methods, vol. 65, no. 1-2, pp. 55-63, 1983.

[21] H. Y. Jo, Y. Kim, H. W. Park et al., "The unreliability of MTT assay in the cytotoxic test of primary cultured glioblastoma cells," Experimental Neurobiology, vol. 24, no. 3, pp. 235-245, 2015.

[22] J. T. MacGregor, J. A. Heddle, M. Hite et al., "Guidelines for the conduct of micronucleus assays in mammalian bone marrow erythrocytes," Mutation Research/Genetic Toxicology, vol. 189, no. 2, pp. 103-112, 1987.

[23] R. Julian Preston, B. J. Dean, S. Galloway, H. Holden, A. F. McFee, and M. Shelby, "Mammalian in vivo cytogenetic assays Analysis of chromosome aberrations in bone marrow cells," Mutation Research/Genetic Toxicology, vol. 189, no. 2, pp. 157$165,1987$.

[24] N. P. Singh, M. T. McCoy, R. R. Tice, and E. L. Schneider, "A simple technique for quantitation of low levels of DNA damage in individual cells," Experimental Cell Research, vol. 175, no. 1, pp. 184-191, 1988.

[25] W. Schmid, "The micronucleus test," Mutation Research/ Environmental Mutagenesis and Related Subjects, vol. 31, no. 1, pp. 9-15, 1975.
[26] F. Bruxel, M. Laux, L. B. Wild, M. Fraga, L. S. Koester, and H. F. Teixeira, "Nanoemulsões como sistemas de liberação parenteral de fármacos," Química Nova, vol. 35, no. 9, pp. 1827-1840, 2012.

[27] Y. I. Cong, C. Pang, L. Dai, G. T. Banta, H. Selck, and V. E. Forbesy, "Importance of characterizing nanoparticles before conducting toxicity tests," Integrated Environmental Assessment and Management, vol. 7, no. 3, pp. 502-503, 2011.

[28] Malvern Instruments Ltd, “Zetasizer Nano Series User Manual," MAN0317, no. 2.1, July 2004, http://www.biozentrum.unibas.ch/ fileadmin/redaktion/Forschung/Research_Groups/BF/instruments/zetasizer_manual.pdf.

[29] S. Alam, S. Baboota, M. Sajid Ali et al., "Accelerated stability testing of Betamethasone dipropionate nanoemulsion," International Journal of Pharmacy and Pharmaceutical Sciences, vol. 4, no. 4, pp. 371-374, 2012.

[30] M. S. Alam, M. S. Ali, M. I. Alam, T. Anwer, and M. M. A. Safhi, "Stability testing of beclomethasone dipropionate nanoemulsion," Tropical Journal of Pharmaceutical Research, vol. 14, no. 1, pp. 15-20, 2015.

[31] R. Parveen, S. Baboota, J. Ali, A. Ahuja, and S. Ahmad, "Stability studies of silymarin nanoemulsion containing Tween 80 as a surfactant," Journal of Pharmacy and Bioallied Sciences, vol. 7, no. 4, pp. 321-324, 2015.

[32] M. Theiszova, S. Jantova, J. Dragunova, P. Grznarova, and M. Palou, "Comparison the cytotoxicity of hydroxyapatite measured by direct cell counting and MTT test in murine fibroblast NIH-3T3 cells," Biomedical Papers, vol. 149, no. 2, pp. 393-396, 2005.

[33] M. Danihelová, M. Veverka, E. Šturdík, and S. Jantová, “Antioxidant action and cytotoxicity on HeLa and NIH-3T3 cells of new quercetin derivatives," Interdisciplinary Toxicology, vol. 6, no. 4, pp. 209-216, 2013.

[34] Y. Cetin and L. B. Bullerman, "Cytotoxicity of Fusarium mycotoxins to mammalian cell cultures as determined by the MTT bioassay," Food and Chemical Toxicology, vol. 43, no. 5, pp. 755764, 2005.

[35] L. Kiss, F. R. Walter, A. Bocsik et al., "Kinetic analysis of the toxicity of pharmaceutical excipients cremophor EL and RH40 on endothelial and epithelial cells," Journal of Pharmaceutical Sciences, vol. 102, no. 4, pp. 1173-1181, 2013.

[36] H. Ding and Y. Ma, "Theoretical and computational investigations of nanoparticle-biomembrane interactions in cellular delivery," Small, vol. 11, no. 9-10, pp. 1055-1071, 2015.

[37] S. A. Chime, F. C. Kenechukwu, and A. A. Attama, "Nanoemulsions-advances in formulation, characterization and applications in drug delivery," in Application of Nanotechnology in Drug Delivery, InTech, Rijeka, Croatia, 2014.

[38] R. P. Patel and J. R. Joshi, "An overview on nanoemulsion: a novel approach," International Journal of Pharmaceutical Sciences and Research, vol. 3, no. 12, pp. 4640-4650, 2012.

[39] A. Watanabe, H. Tanaka, Y. Sakurai et al., "Effect of particle size on their accumulation in an inflammatory lesion in a dextran sulfate sodium (DSS)-induced colitis model," International Journal of Pharmaceutics, vol. 509, no. 1-2, pp. 118-122, 2016.

[40] J. Manosroi, P. Dhumtanom, and A. Manosroi, "Anti-proliferative activity of essential oil extracted from Thai medicinal plants on KB and P388 cell lines," Cancer Letters, vol. 235, no. 1, pp. 114-120, 2006.

[41] M. A. Moreno, M. P. Ballesteros, and P. Frutos, "Lecithin-based oil-in-water microemulsions for parenteral use: pseudoternary phase diagrams, characterization and toxicity studies," Journal of Pharmaceutical Sciences, vol. 92, no. 7, pp. 1428-1437, 2003. 
[42] J. Wang, Y. Maitani, and K. Takayama, "Antitumor effects and pharmacokinetics of aclacinomycin A carried by injectable emulsions composed of vitamin E, cholesterol, and PEG-lipid," Journal of Pharmaceutical Sciences, vol. 91, no. 4, pp. 1128-1134, 2002.

[43] M. S. Bangale, S. S. Mitkare, S. G. Gattani, and D. M. Sakarkar, "Recent nanotechnological aspects in cosmetics and dermatological preparations," International Journal of Pharmacy and Pharmaceutical Sciences, vol. 4, no. 2, pp. 88-97, 2012.

[44] J.-L. Gesztesi, L. M. Santos, P. T. Hennies, and K. A. Macian, "Oil-in-water nanoemulsion, acosmetic composition and acosmetic product comprising it, aprocess for preparing saidnanoemulsion," United States Patent. No. US 8,956,597 B2, 2015, https://www.google.com/patents/US8956597.

[45] U. Sakulku, O. Nuchuchua, N. Uawongyart, S. Puttipipatkhachorn, A. Soottitantawat, and U. Ruktanonchai, "Characterization and mosquito repellent activity of citronella oil nanoemulsion," International Journal of Pharmaceutics, vol. 372, no. 1-2, pp. 105-111, 2009.

[46] G. L. Amidon, H. Lennernäs, V. P. Shah, and J. R. Crison, "A theoretical basis for a biopharmaceutic drug classification: the correlation of in vitro drug product dissolution and in vivo bioavailability," Pharmaceutical Research, vol. 12, no. 3, pp. 413420, 1995.

[47] V. W. C. Wong, Y. T. Szeto, A. R. Collins, and I. F. F. Benzie, "The COMET assay: a biomonitoring tool for nutraceutical research," Current Topics in Nutraceutical Research, vol. 3, no. 1, pp. 1-14, 2005.

[48] G. A. Asare, B. Gyan, K. Bugyei et al., "Toxicity potentials of the nutraceutical Moringa oleifera at supra-supplementation levels," Journal of Ethnopharmacology, vol. 139, no. 1, pp. 265-272, 2012.

[49] P. Venkatesh, B. Shantala, G. C. Jagetia, K. K. Rao, and M. S. Baliga, "Modulation of doxorubicin-induced genotoxicity by Aegle marmelos in mouse bone marrow: a micronucleus study," Integrative Cancer Therapies, vol. 6, no. 1, pp. 42-53, 2007.

[50] L. S. Almeida, J. R. Gama, F. d. Oliveira, J. O. Carvalho, D. C. Gonçalves, and G. C. Araújo, "Fitossociologia e uso múltiplo de espécies arbóreas em floresta manejada, comunidade Santo Antônio, município de Santarém, estado do Pará," Acta Amazonica, vol. 42, no. 2, pp. 185-194, 2012.

[51] M. Luo, L. Jiang, and G. Zou, "Acute and genetic toxicity of essential oil extracted from Litsea cubeba (Lour.) Pers.," Journal of Food Protection, vol. 68, no. 3, pp. 581-588, 2005.

[52] A. E. M. F. M. Oliveira, J. L. Duarte, J. R. R. Amado et al., "Development of a larvicidal nanoemulsion with Pterodon emarginatus vogel oil," PLoS ONE, vol. 11, no. 1, Article ID e0145835, 2016. 

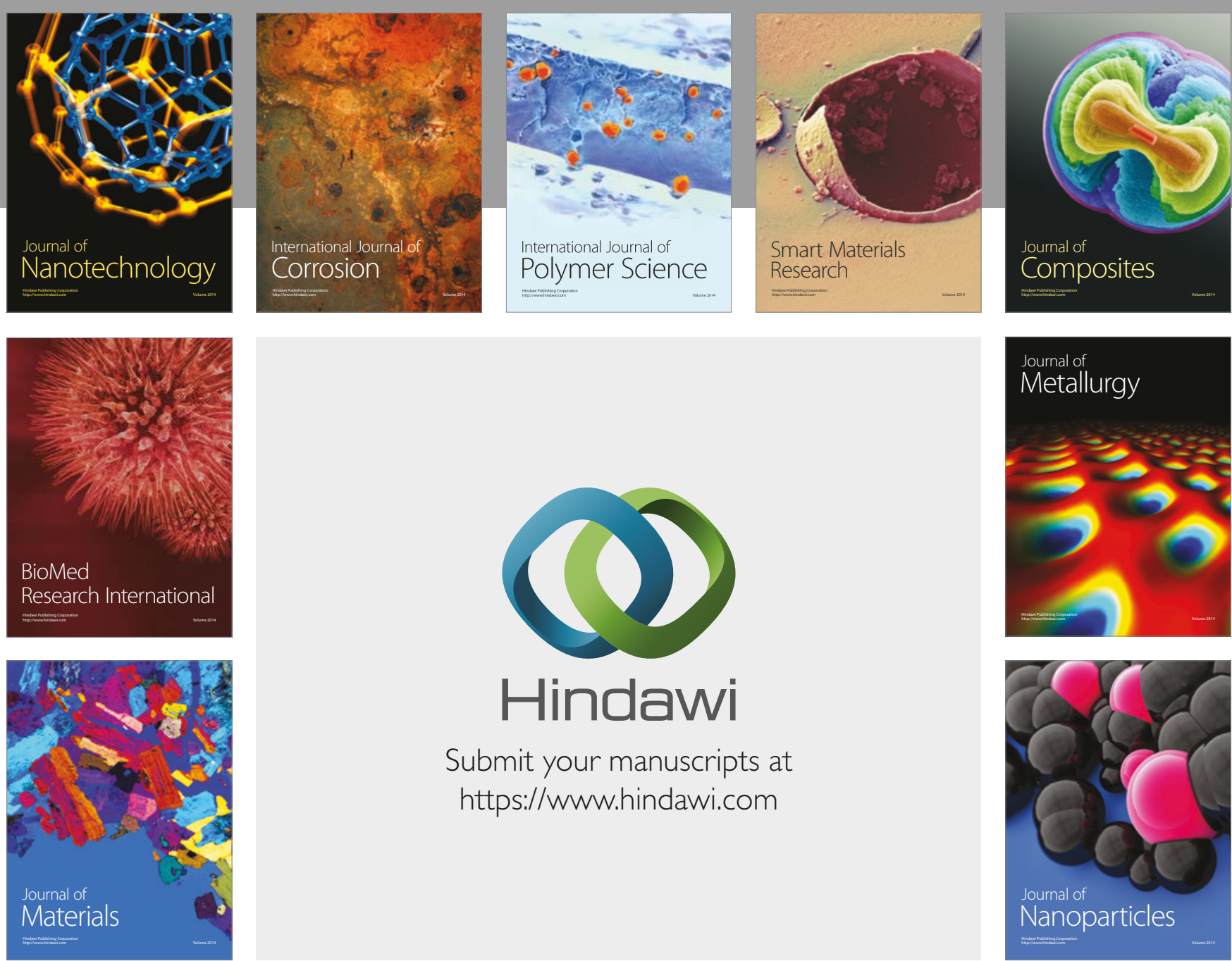

\section{Hindawi}

Submit your manuscripts at

https://www.hindawi.com
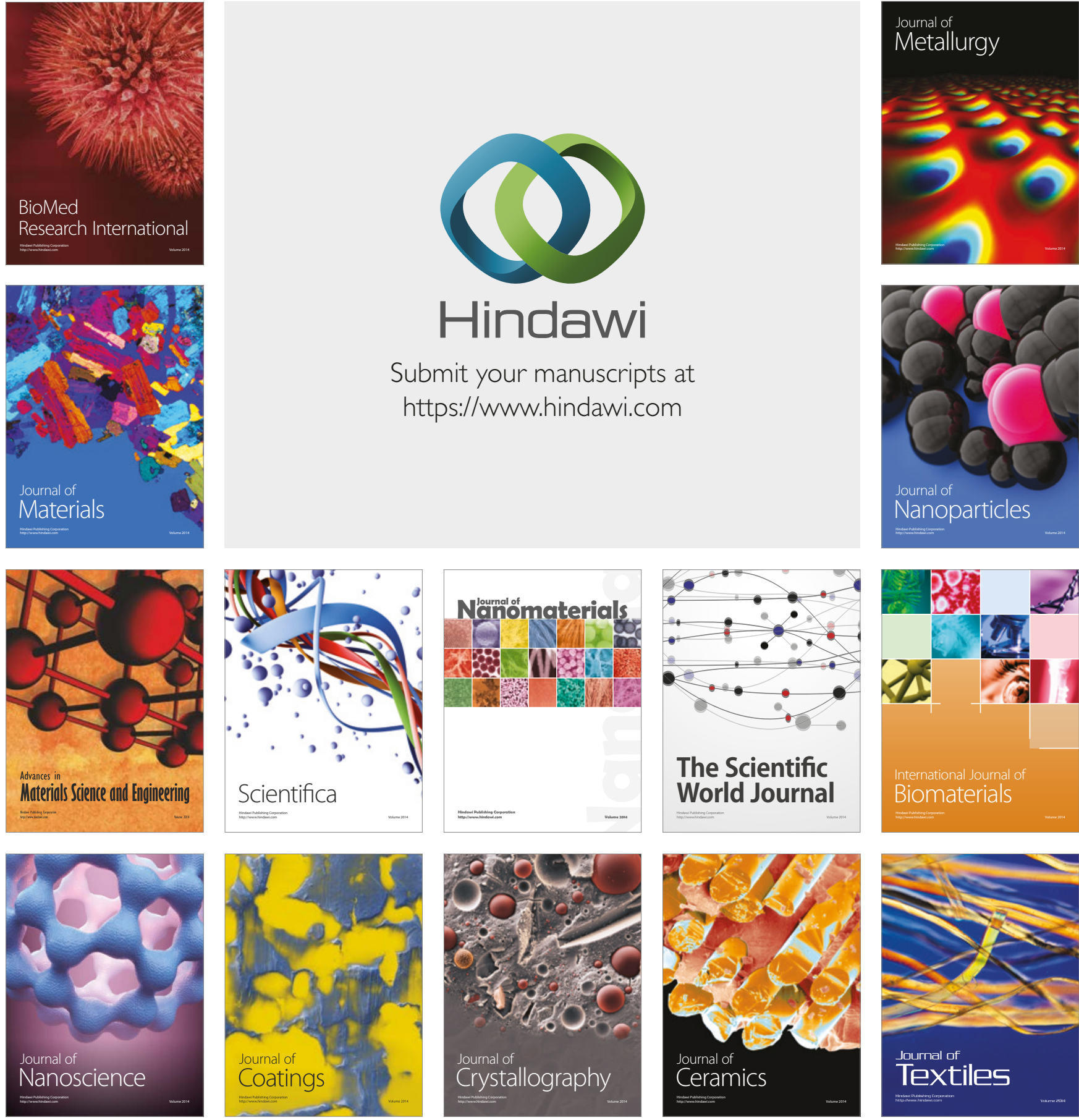

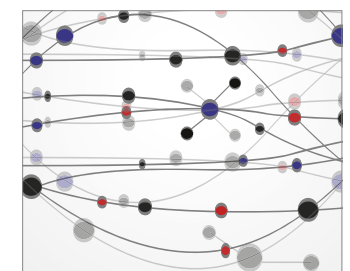

The Scientific World Journal
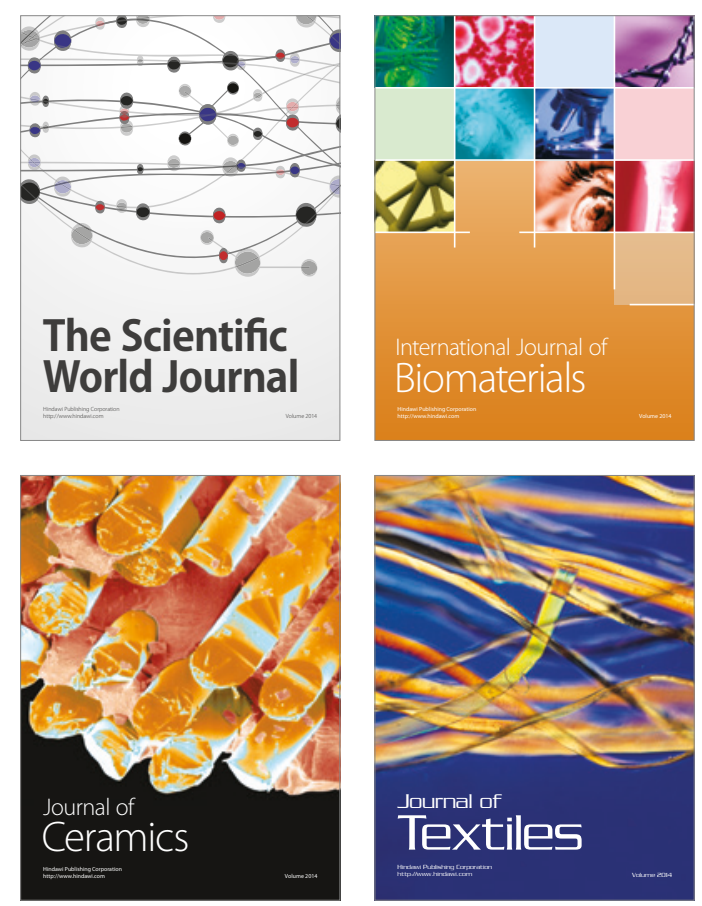